\title{
SWOT Research on Domestic Third-Party Logistics Providers (3PLPs) in China
}

\author{
YU LIU \\ Finance and Economic School, XI ZANG MIN ZU University, China \\ XIAN YANG City, 710082, China \\ Email:191017804@qq.com
}

Key Words: Domestic Third-Party Logistics Providers (3PLPs), SWOT, Development strategy

\begin{abstract}
With the rapid growth of logistics, it is important to gain further insight into the strategic benefits of logistics services. The study examines the current situation of domestic 3PLPs. Based on this, the study analyses domestic 3PLPs in China from four aspects (strengths, weakness, opportunity, threat) with SWOT method. Finally, the study recommends the development strategies to strengthen competitive power of global 3PLPs in China. This study provides a theoretical foundation for academics and also practical guidelines for logistics services industry
\end{abstract}

\section{Introduction}

Logistics is widely recognized as an important ingredient for a country to succeed in the globalization era. The development level of the logistics industry in a country reflects its national power and overall competitiveness. With this circumstance, more and more companies have realized the importance of logistics, and consider logistics outsourcing as their main strategy to achieve competitive advantages. Therefore, it is an unavoidable issue for 3PLPs how to improve service quality and strength the competitive power.

In Chinese logistics service industry, there are three main distinct groups coming from different origins. They are traditional central or state-owned transport and warehouse enterprises, for example China Shipping (Group) Company; private logistics enterprises, for example Gongsuda Logistics (Shenzhen),Co.,LTD; Sinoforeign or foreign-capital logistics enterprises, for example S.F. Express. From the 50list of logistics enterprises, it is still dominant for the central or state-owned logistics enterprises.

Based on above, the research purpose of this study is stated below: Firstly, the paper examines the current situation and In-company situation of 3PLPs. Based on the discussed background, the study analyses domestic 3PLPs in China from four aspects (strengths, weakness, opportunity, threat) with SWOT method. Finally, the study recommends development strategies to strengthen competitive power of global 3PLPs in China.

\section{SWOT Analysis on Domestic 3PLPs}

Based on above, an overall SWOT analysis summarizes the strengths, weakness, opportunities, and threats of the 3PLPs, which provides an overall picture and a summary of how the companies 
understand their competitive situations.

\subsection{Strengths}

\subsection{Physical Distribution Networks provided are more comprehensive.}

The main logistics companies chosen come from the areas of Pearl River Delta and Chang Jiang River Delta, which is the most developed coastal area in China, and the logistics industry there has developed faster than other areas of the country. The most common factor found is that the networks of the companies have been established and spread across the country.

\subsubsection{Services provided are more diversified.}

With the development of third-party logistics in China, the companies have moved their attention to multifunctional logistics services, such as transportation distribution, warehousing, and inventory management. Further, with the dynamic introduction and development of the notion of supply chain management, these companies start to provide some value-added services and supply chain solution services that were motivated by the increasing requirements from customers.

\subsubsection{Information Technology Systems provided are more advancing.}

Information technology has been addressed as an important driver of supply chain management. Interestingly, the companies involved are all equipped with different information systems that comprise similar functional information technologies. All of these indicate that the information technology Chinese 3PLPs are using has developed and improved significantly, which can be updated finding of the information technology situation in Chinese third-party logistics industry

Based on the competitive strengths, the companies have achieved constant increase in their sales in the past two years which shows the overall increasing trend in different companies in different years.

\subsubsection{Weaknesses}

\subsubsection{PLPs are still in its primary stage.}

As the logistics companies were chosen from the list of 2014 top 50 logistics companies in China, they can be recognized as the most developed 3PLPs in Chinese 3PL industry. Concerning its origin, it is similar to the development of third-party logistics in other counties. However, the starting time period seems a little later than what happened in the developed countries. This may be the reason why the third-party logistics in China is described as still "young", "in its infancy" or "different from the developed countries".

\subsubsection{Price competition for 3PLPs is intensive.}

Attending bidding is the main way for 3PLPs to gain business. In China, immature 3PL users are more likely to adopt bidding as their main strategy in selecting 3PLPs, and most of the biding may directly lead to price competition among the 3PLPs. The results of such biding are endless price competition and frequent switch in 3PL. Immature 3PL usage is one main reason leading to endless price competition, frequent switch in 3PL, and finally chaotic competition. Therefore, 3PLPs do not have strength in pure price competition. 


\subsubsection{Integrated services and management skills for 3PLPs are shortage.}

Foreign 3PLPs have advantages in not only cost but also service and management. For foreign 3PLPs with advanced management experience, they provide perfect integrated services and have the competitive edge in SCM and IT. They can more easily satisfying the needs of client firms.

\subsection{Opportunities}

\subsubsection{Logistics Market Demand is increasing.}

Logistics industry will enter a new development stage. Logistics industry in China has progressed from a relatively primitive stage to a stage of rapid growth. The next decade or two is seen as a golden age for further development. Some experts predicted that the industry would grow at anannual rate of $20 \%$; and that the overall logistics cost of the country would go down to less than $15 \%$ of the GDP in the next 10 years.

\subsubsection{Logistics Services Infrastructure is enhancing.}

The development of inter-modal transportation is promoting. In fact, the central government has made strong efforts to step up the construction of infrastructure at the beginning of the post-WTO era. For example, it laid out an ambitious transport infrastructure plan in its Five-year Plans (from 10th to 13th), which set aside massive spending on infrastructure development, from roads to ports, in different provinces and regions. For example, building logistics parks are on the drawing boards of many provinces and cities including Guangzhou, Shenzhen, Beijing, Shanghai, Tianjin, Wuhan, Chongqing, Dalian and Xian, even concluding Xizang. Being an advanced productive force, Chinese modern logistics is making greater contribution to the national economy.

\subsubsection{Government Logistics Policies are being improved.}

The 13 Five-Year Plan emphasizes the need to develop the capacity of third party logistics companies and modernization of logistics services. As a response, the Ministry is introducing measures for the establishment of large-sized port groups and third party logistics companies. Transport companies and intermediary service providers are encouraged and guided to expand operational scope and work on brand building. The support for enhancing outsourcing in the industry can also strengthen the development of third party logistics providers. To support the long term development of the industry, the Ministry is also promoting the technological advancement of logistics industry.

\subsection{Threats}

\subsubsection{Logistics environment is still imperfect.}

Although the total logistics cost of GDP is declining in China, it is still more than double the $10 \%$ share in the developed countries such as the US and Japan, reflecting that the development of logistics services industry still has a long way to go. The main logistics centers, information and communications technology is unreliable in China. There are a lack of IT standards and poor systems integration and equipment. Also, due to energy prices rising, power of competitiveness is shrinking. Rising prices led to an increase in investment risk and make domestic logistics companies negative about investing, which will eventually make them uncompetitive in the market. In addition, foreign global companies are becoming ever larger through strategic alliances and 
M\&A and are exercising their influence in pricing of logistics market. These will not only hinder domestic logistics business from pursuing globalization but also will seize domestic logistics market share

\subsubsection{Government limitation and local protection are still existed.}

No government authority involved in the whole logistics sector. For example, three ministries, Ministry of Transportation, Ministry of Railway and Civil Aviation Administration of China are in charge of highway, railway and airway issues, respectively. Lack of coordination between these authorities has resulted in low efficiency, duplicate infrastructure and overlaps in the roles of different authorities. In addition, Historically formed local protectionism and persistent bureaucracy are the roots of the unfair competition.

\subsubsection{Detachments of logistic-related departments are hindered.}

Under the planned economy, most of Chinese manufacturing or commercial enterprises established in house transportation and warehousing departments to serve themselves because of the shortage of third-party supply. With the development of the Chinese economy, many of firms intend to detach those logistics-related departments and use third-party services. However, some barriers, such as staff reallocation and managers' fear of controlling power loss have deterred the detachment significantly, which has curbed the demand for external logistics services and restricted the industry's development.

\section{Strategies to Enhance Competitive Power of Domestic 3PLPs}

Through SWOT analysis, it is not difficult to conclude that domestic 3PLPs have implemented similar strategy in development process. The common characteristics of Strategies can be summarized as follows:

\subsection{Development of competitive strategy}

Competition is intensive in the Chinese third-party logistics industry. 3PLPs must be competitive to survive to thrive in the challenging environment. Market segment selection has been a critical step for logistics companies to achieve competitive advantages within an intensive competition environment. Competitive strategies have been developed the two generic strategies as cost leadership strategy (or value advantage) and service leadership strategy (or productivity advantage). The aim of competitive strategies is cost advantages and differentiation focus in their positioned market segment. According to related research, a 3PIP may compete as a service leader trying to gain value advantages over its competitors by providing various services to achieve differentiation. Meanwhile, the company may compete as a cost leader, trying to utilize and optimize its resources so that the company can offer services at the lowest cost.

\subsection{Development of distribution networks strategy}

The physical distribution function is a complex process which consists of all the activities involved in the flow of goods from suppliers to final consumers. The goal of distribution network operation is to achieve desirable customer service levels at a minimum total cost. Obviously, an effective physical logistics network is critical for successful logistics operation; it can be strongly related to the achievement of both cost and service competitive advantages.

\subsection{Development of IT system strategy}

Information has been identified as one of the main drivers of the supply chain. Information has always been central to the efficient management of logistics but now, enabled by technology, it is 
providing the driving force for competitive logistics strategy. IT systems may aid the decision-making process, help to monitor and control operations, create simulated systems, store and process data, and aid communication between individuals, companies and machines. With the fierce competition, logistics companies are willing to invest in IT introduction and development. The willingness toward IT investment shows how these 3PLPs view the significance of IT in helping them to achieve logistics process.

\subsection{Development of customer relationship strategy}

Traditionally, customer relationships have been viewed as buyer and seller relationships, which are adversarial relationships and are very common in traditional business environment. With the increasing growth in logistics outsourcing, more and more companies are entering into long-term relationships with their 3PLPs. The ability to sophistically manage third-party relationships has become a main factor of successful logistics outsourcing. Therefore, customer relationship has been a strategic focus of the provision of logistics services. The current situations discussed before have indicated that logistics companies provided not only single logistics services but also value-added services and supply chain solution services. This means the complexity of service varies from simple to complex, whereas the customer relationship various from loose to close. The cooperation situation requires the companies to elevate the normal transactional relationships to strategic stage.

\subsection{Development of alliances strategy}

The establishment of alliance strategy is a suitable choice for some Chinese logistics service providers. With greater competition and higher-level requirements for logistics operation, domestic logistics firms are required to provide more comprehensive service activities, and cover broader business market with high-level business performance. However, the internal activities and acquisitions could be hindered by the limited capital capability, which is the current status of many local firms. Under this situation, the establishment of strategic alliances and going for long-term strategic benefits for both partners become an appropriate choice.

\section{Acknowledgements}

In this paper, the research was sponsored by the Major Project Cultivation Program of XI ZANG MIN ZU University (Project No. 17MDZP01).

\section{References}

[1] Zhou, G., Min, H., Xu, C., and Cao, Z. (2008), evaluating the comparative efficiency of Chinese third-party logistics providers using data envelopment analysis, International Journal of physical distribution \& logistics management, Vol. 38, No. 4, pp. 262-279.

[2] S.J. Shen, "The analysis of supply and demand in China's logistics market" Logistics Technology and Applications, Vol. 5 No. 2, February, 2005, pp 5-11.

[3]L. Fung Research Centre, Recent development of the logistics industry in China (2004-2005) ,China Distribution \& Trading Issue 27 June 2005

[4] Hong, J.J., Chin, A. and Liu, B.L. (2004b), “Firm-specific characteristics and logistics outsourcing by Chinese manufacturers”, Asia Pacific Journal of Marketing and Logistics, Vol. 16 No. 3, pp. 23-36.

[5]Anthony and L.Bing lian, Logistics service providers in China, Current status and future prospects Asia Pacific $\begin{array}{lllllll}\text { Journal of } & \text { Marketing and }\end{array}$ $\begin{array}{lccc}\text { 2007pp.168-18,Emeraldwww.emeraldinsight.com/1355-5855.htm } & \\ \text { [6] China } & \text { Logistics } & \text { Industry }\end{array}$ 2010-2011, http://www.researchinchina.com/FreeReport/PdfFile/634459940643976250.pdf

[7] China Air Transport and Airport Industry Report, 2009-2010 http://www.researchinchina.com/htmls/Report/2010/5892.html 
[8]China Railway Transport $\quad$ Equipment $\quad$ Industry $2009-2010$ http://www.researchinchina.com/htmls/Report/2010/5868.html [9]China Ports Industry Report, 2009 http://www.researchinchina.com/htmls/Report/2009/5756.html 